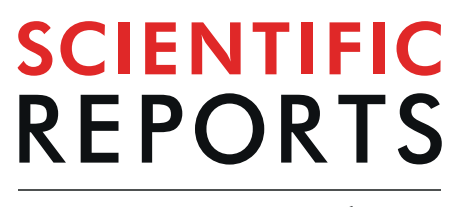

natureresearch

\title{
Assessment of metals induced histopathological and gene expression changes in different organs of non-diabetic and diabetic rats
}

\author{
Muhammad Ahsan Riaz ${ }^{1 *}$, Zaib Un Nisa ${ }^{1}$, Muhammad Sohail Anjum², Hira Butt $\mathbb{D}^{2}$, \\ Azra Mehmood ${ }^{2}$, Ayesha Riaz ${ }^{3}$ \& Amtul Bari Tabinda Akhtar ${ }^{4}$
}

Diabetes is a complex metabolic disorder and different environmental toxicants including heavy metals have been involved in diabetes induction. Therefore, assessment of the environmental risk factors and heavy metals induced toxicity have become critical for reducing the consequences of metals pollutants. Previously, we reported heavy metals induced nephrotoxicity in non-diabetic and diabetic rats. Here, we extended our analysis by examining the heavy metals induced organs (heart, kidney, liver, pancreas, and spleen) damage in diabetic and non-diabetic Wistar rats using histopathology and quantitative real-time PCR (qRT-PCR). Following the generation of the diabetic rat model, the animals were exposed to heavy metals including lead $(\mathrm{Pb})$, arsenic ( $\mathrm{As})$, manganese $(\mathrm{Mn})$ and cadmium (Cd). Both non-diabetic and diabetic rats were exposed to heavy metals for 30 days and subsequently, the heart, kidney, liver, pancreas and spleen tissues were examined. Heavy metal treatment resulted in irregularly arranged myofibrils and vacuolization in the heart tissue of metal treated groups as evident from hematoxylin and eosin ( $\mathrm{H} \& \mathrm{E}$ ) staining. The kidney tissue of rats treated with heavy metals showed tubular degeneration, fibrosis, hemorrhage, and vacuolation. The liver of the heavy metals treated rats exhibited cellular degeneration and necrosis. The pancreatic tissue of streptozotocin injected untreated and metal treated rats revealed severe degeneration, necrosis, degranulation, shrinkage, and depression in the islets of Langerhans. Increased red pulp area and congestion were observed in the spleen of the metal mixture treated non-diabetic and diabetic rats. In line with the histological data, the qRT-PCR analysis showed downregulated expression of $\mathrm{BCl}_{2}$ and upregulation of Caspase-3 in nondiabetic and diabetic metal treated rats as compared to the non-diabetic untreated rats. In conclusion, the present study revealed, diabetic rats are more prone to metal alone as well as metal mixture induced organ damage as compared to non-diabetic rats.

Diabetes is a metabolic disorder, characterized by impaired insulin secretion, fasting hyperglycemia or insulin receptor insensitivity. The prevalence of diabetes is increasing all over the world and increased from $4.7 \%$ in 1980 to $8.5 \%$ in $2014^{1}$. Diabetes is the $7^{\text {th }}$ leading cause of mortality in the United States and worldwide and results in serious complications including kidney disease, cardiovascular disease, blindness, etc., ${ }^{1,2}$. It is well documented that environmental exposure to synthetic or naturally occurring chemical elements contribute to diabetes induction $^{3-5}$. Metals are essential components of biological functions, while their higher concentrations can be toxic $^{6,7}$. Cadmium $(\mathrm{Cd})$, arsenic (As), cobalt $(\mathrm{Co})$, mercury $(\mathrm{Hg})$, manganese $(\mathrm{Mn})$ and lead $(\mathrm{Pb})$ are known as endocrine-disrupting chemicals ${ }^{8,9}$. Importantly, $\mathrm{Pb}, \mathrm{As}, \mathrm{Mn}$ and Cd play a crucial role in public health issues ${ }^{10}$.

\footnotetext{
${ }^{1}$ Department of Environmental Sciences and Engineering, Government College University, Faisalabad, Pakistan. ${ }^{2}$ National Centre of Excellence in Molecular Biology, University of the Punjab, Lahore, Pakistan. ${ }^{3}$ Department of Zoology, Government College Women University, Faisalabad, Pakistan. ${ }^{4}$ Sustainable Development Study Center, Government College University, Lahore, Pakistan. *email: ahsanenv38@gmail.com
} 
Several groups have reported that heavy metals induce toxicity at low concentrations ${ }^{11,12}$. Humans are exposed to heavy metals through water, food or inhalation. Metals readily accumulate in tissues of vital organs via contaminated air, water ${ }^{13}$ and food ${ }^{14}$ resulting in long-term toxic effects. Concentrations of trace elements affect a range of organs in both humans and animals ${ }^{15}$. Heavy metal water and air contamination is a global issue especially in developing countries ${ }^{16,17}$. $\mathrm{Pb}$ toxicity in both acute and chronic exposure has the potential to cause many deleterious systematic effects at the cellular level and eventually resulting in different diseases ${ }^{18}$. As, is known as carcinogenic chemical and responsible for toxicity in kidney, lung, skin, urinary bladder, liver and prostate ${ }^{19}$. The Cd toxicity results in physiological damage to transport proteins and mitochondria and causes apoptosis in different organs such as liver, kidney, skin, lungs and reproductive organs ${ }^{20}$. Overexposure to $\mathrm{Mn}$ has been reported to generate reactive oxygen species (ROS) and cause extensive neural, cardiovascular and hepatic damage ${ }^{21}$. Research on the toxic effects of individual heavy metal as well as metal mixture under diabetic conditions especially the effects of heavy metals at the molecular level are scarce.

Previously, we reported metal-induced nephrotoxicity in diabetic and non-diabetic Wistar rats ${ }^{22}$. Here, we aimed to investigate the effects of metal alone as well as metal mixture ( $\mathrm{Pb}, \mathrm{Cd}, \mathrm{Mn}$, and $\mathrm{As})$ induced toxicity in different body organs including heart, liver, pancreas, spleen, and kidney at molecular level in diabetic and non-diabetic Wistar rats using histopathology and quantitative real-time PCR (qRT-PCR) analyses.

\section{Results}

Here, we examined the metal alone as well as a metal mixture ( $\mathrm{Pb}, \mathrm{Mn}, \mathrm{Cd}$, and As) induced histopathological changes in different organs (heart, kidney, liver, pancreas, and spleen) of non-diabetic and diabetic Wistar rats. The histological examination of heart tissue from non-diabetic and diabetic rats following heavy metal exposure was performed using a light microscope. To assess the impact of heavy metals on the heart, myocardial tissue was stained with hematoxylin and eosin $(\mathrm{H} \& \mathrm{E})$. The heart tissue of the non-diabetic untreated control group revealed no histopathological changes including distinct myofibrils arrangement and no congestion in vessels (Fig. 1a). Heavy metal treatment resulted in severe heart damage in the diabetic metal mixture treated group (Fig. 11). Histological examination of metals treated heart tissue of rat demonstrated irregularly arranged myofibrils and vacuolization (Fig. 1b-1). The effects of heavy metal exposure to non-diabetic and diabetic rats were also evaluated by gene expression analysis for anti-apoptotic and apoptotic markers such as $\mathrm{Bcl}_{2}$, and Caspase-3 respectively, using qRT-PCR analysis. To investigate the impact of heavy metals on heart tissue, following RNA extraction and cDNA synthesis, the qRT-PCR analysis was performed. Heavy metal treatment resulted in a downregulated expression of $\mathrm{Bcl}_{2}$ in non-diabetic and diabetic metal alone as well as in metal mixture treated groups in comparison with the non-diabetic untreated control group as shown in Supplementary Fig. 1a. The qRT-PCR analysis revealed that apoptotic gene Caspase-3 was significantly upregulated in non-diabetic and diabetic metal alone and metal mixture treated groups in comparison with the non-diabetic untreated control group as shown in Supplementary Fig. $1 \mathrm{~b}$.

The histological examination of kidney tissue from the non-diabetic untreated control rats following $\mathrm{H} \&$ E staining showed normal structure (Fig. 2a), whereas, the kidney tissue from the rats treated with heavy metals exhibited tubular degeneration, fibrosis, hemorrhage and vacuolation (Fig. 2b-l). In Cd-treated, Pb-treated and metal mixture treated non-diabetic as well as diabetic rats, there was an increased severity of pathological changes including red blood cells (RBCs) deposited in capillaries, clogged blood vessels and interstitial fibrosis (Fig. 2c,e,f,i,k,l). In conclusion, exposure to heavy metals resulted in nephrotoxicity in rats. Gene expression analysis of kidney tissue for $\mathrm{BCl}_{2}$ and Caspase-3 following heavy metal treatment revealed downregulated expression of $\mathrm{Bcl}_{2}$ in non-diabetic and diabetic metal alone and metal mixture treated groups as compared to the non-diabetic untreated control group as shown in Supplementary Fig. 2a. The qRT-PCR analysis revealed that apoptotic gene Caspase- 3 was significantly upregulated in non-diabetic and diabetic metal alone and metal mixture treated groups as compared to the non-diabetic untreated control group as shown in Supplementary Fig. 2 b.

The liver tissue of the non-diabetic untreated control group rats showed no histopathological alterations and exhibited normal hepatocyte structure as evident from H \& E staining (Fig. 3a). However, liver tissue of heavy metals treated rats had cellular degeneration and necrosis (Fig. 3b-1). Further, metal mixture treated rats showed vacuolation and inflammation in the liver in addition to cellular degeneration (Fig. 3f,l). The effects of heavy metal exposure to non-diabetic and diabetic rats were also evaluated by gene expression analysis for anti-apoptotic and apoptotic markers such as $\mathrm{Bcl}_{2}$, and Caspase-3 using qRT-PCR. Heavy metal treatment resulted in a downregulated expression of $\mathrm{BCl}_{2}$ in non-diabetic and diabetic metal alone and metal mixture treated groups as compared to the non-diabetic untreated control group as shown in Supplementary Fig. 3a. The qRT-PCR analysis revealed that apoptotic gene Caspase-3 was significantly upregulated in non-diabetic and diabetic metal alone and metal mixture treated groups as compared to the non-diabetic untreated control group as shown in Supplementary Fig. 3b.

The pancreas of the non-diabetic untreated control group rats showed the normal histological morphology (Fig. 4a). In streptozotocin injected untreated rats, severe degeneration and necrosis were observed in pancreatic tissue (Fig. 4g). In diabetic metal treated rats, the most consistent findings in the histologic sections of pancreatic tissues were severe degeneration, necrosis, degranulation and shrinkage in the islets of Langerhans (Fig. 4h-1). The qRT-PCR analysis of pancreas tissue from non-diabetic and diabetic rats following heavy metal treatment exhibited downregulated expression of $\mathrm{Bcl}_{2}$ in non-diabetic and diabetic metal alone and metal mixture treated groups as compared to the non-diabetic untreated control group as shown in Supplementary Fig. 4a. The qRT-PCR analysis revealed that apoptotic gene Caspase- 3 was significantly upregulated in non-diabetic and diabetic metal alone and metal mixture treated groups as compared to the non-diabetic untreated control group as shown in Supplementary Fig. 4b.

The images of Fig. 5 show the histopathological sections of the spleen tissue. Severe congestion and enlarged red pulp parts are evident from the spleen tissue of the metal mixture treated non-diabetic and diabetic rats. Severe congestion and necrosis of the spleen tissue are suggestive of heavy metal mixture induced spleen damage (Fig. 5f,1). The effects of metal exposure to non-diabetic and diabetic rats were also assessed by gene expression analysis for anti-apoptotic and apoptotic markers such as $\mathrm{Bcl}_{2}$, and Caspase-3 using qRT-PCR analysis. Metal 

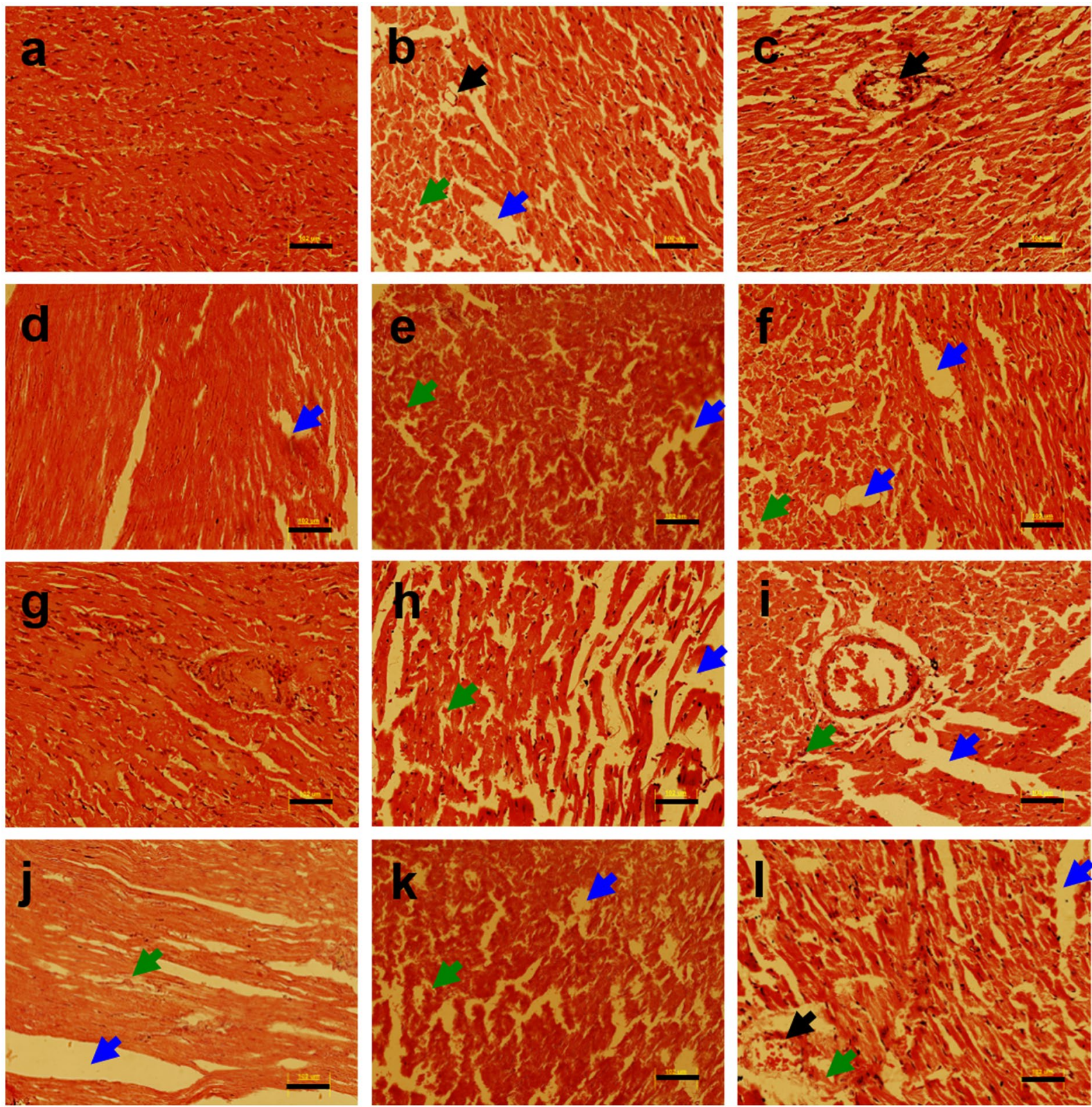

Figure 1. Histopathology of heart tissue of non-diabetic and diabetic rats stained with hematoxylin and eosin $(\mathrm{H} \& \mathrm{E})$ following heavy metal exposure. (a) non-diabetic control group (b) non-diabetic arsenic (As)-treated group, (c) non-diabetic cadmium (Cd)-treated group, (d) non-diabetic manganese (Mn)-treated group, (e) non-diabetic lead $(\mathrm{Pb})$-treated group, (f) non-diabetic metal mixture (As $+\mathrm{Cd}+\mathrm{Mn}+\mathrm{Pb}$ )-treated group, $(\mathbf{g})$ diabetic untreated group, (h) diabetic As-treated group, (i) diabetic Cd-treated group, (j) diabetic Mn-treated group, (k) diabetic $\mathrm{Pb}$-treated group and (l) diabetic metal mixture ( $\mathrm{As}+\mathrm{Cd}+\mathrm{Mn}+\mathrm{Pb}$ )-treated group. Note: All the images represent $\times 20$ magnification and scale bars represent $102 \mu \mathrm{m}$. Further, blue arrows represent vacuolation, green arrows represent cellular degeneration and black arrows represent congestion.

treatment resulted in a downregulated expression of $\mathrm{Bcl}_{2}$ in non-diabetic and diabetic metal alone and metal mixture treated groups as compared to the non-diabetic untreated control group as shown in Supplementary Fig. 5a. The qRT-PCR analysis revealed that apoptotic gene Caspase-3 was significantly upregulated in non-diabetic and diabetic metal alone and metal mixture treated groups in comparison with the non-diabetic untreated control group as shown in Supplementary Fig. 5b.

\section{Discussion}

Previously, we reported metal-induced nephrotoxicity using diabetic and non-diabetic Wistar rats ${ }^{22}$. Here, we extended our analysis employing histopathological and qRT-PCR (for $\mathrm{Bcl}_{2}$ and Caspase-3 expression) analyses to investigate the metal alone as well as metal mixture induced toxicity in different organs including heart, liver, pancreas, and spleen in addition to the kidney of diabetic and non-diabetic Wistar rats. Diabetes is a complex 

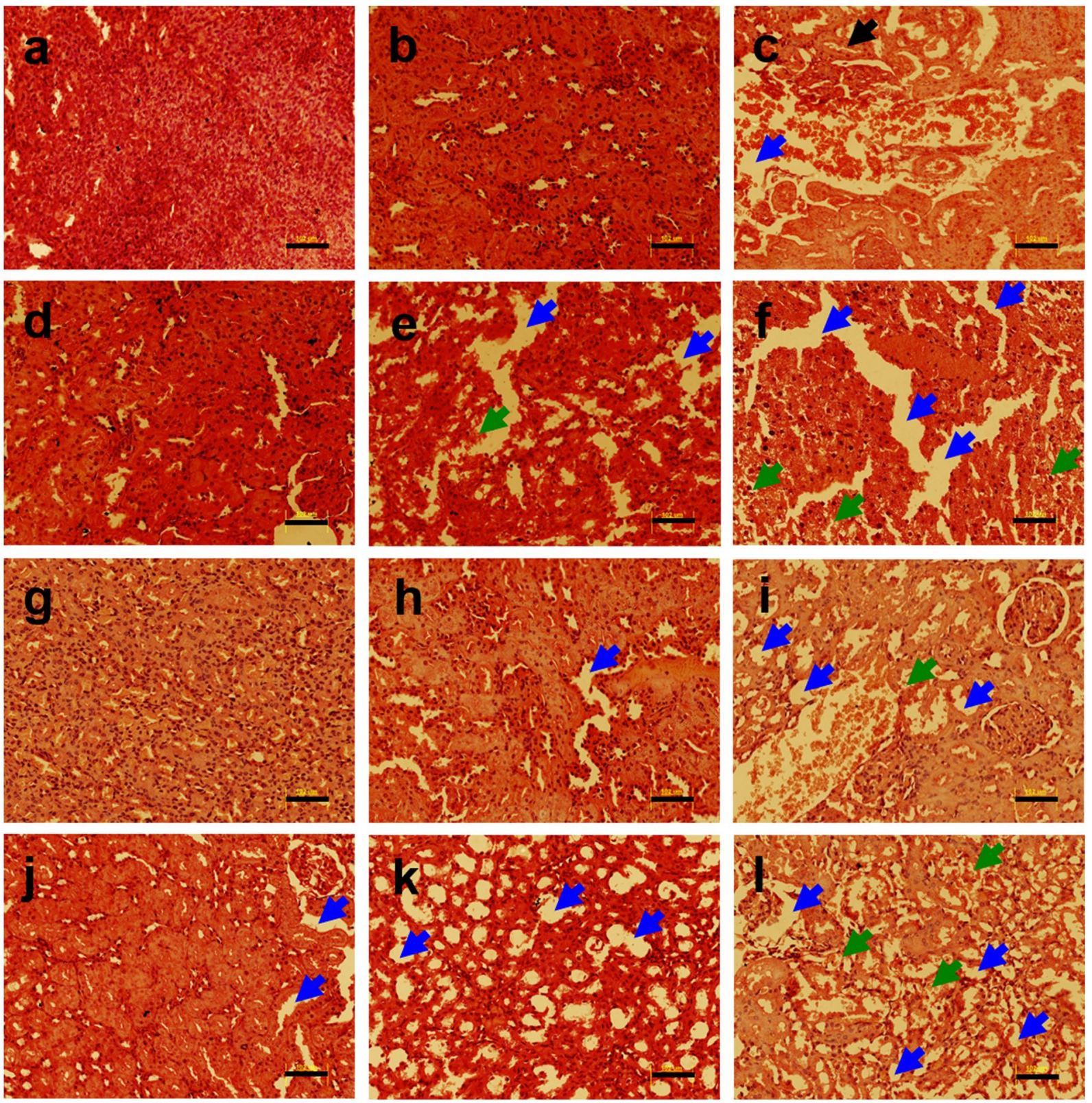

Figure 2. Histopathology of kidney tissue of non-diabetic and diabetic rats stained with hematoxylin and eosin ( $\mathrm{H} \& \mathrm{E}$ ) following heavy metal exposure. (a) non-diabetic control group, (b) non-diabetic arsenic (As)-treated group, (c) non-diabetic cadmium (Cd)-treated group, (d) non-diabetic manganese ( $\mathrm{Mn})$-treated group, (e) non-diabetic lead $(\mathrm{Pb})$-treated group, $(\mathbf{f})$ non-diabetic metal mixture $(\mathrm{As}+\mathrm{Cd}+\mathrm{Mn}+\mathrm{Pb})$-treated group, $(\mathbf{g})$ diabetic untreated group, (h) diabetic As-treated group, (i) diabetic Cd-treated group, (j) diabetic Mn-treated group, (k) diabetic $\mathrm{Pb}$-treated group and (l) diabetic metal mixture ( $\mathrm{As}+\mathrm{Cd}+\mathrm{Mn}+\mathrm{Pb}$ )-treated group. Note: All the images represent $\times 20$ magnification and scale bars represent $102 \mu \mathrm{m}$. Further, blue arrows represent vacuolation, green arrows represent cellular degeneration and black arrows represent congestion.

metabolic disorder ${ }^{13}$ and it is well documented that different toxicants involve in the induction of insulin resistance and contribute to diabetes-related substantial mortalities ${ }^{23,24}$. Apoptosis can be induced by a variety of stimuli including chemotherapy agents ${ }^{25}$, ultraviolet (UV) radiations ${ }^{26}$, polychlorinated biphenyls ${ }^{27}$, infection by pathogens $^{28}$, polycyclic aromatic hydrocarbons $(\mathrm{PAHs})^{29}$ and heavy metals ${ }^{30,31}$. Among these contributing factors, heavy metals take a critical part in the stimulation of apoptosis and eventually leading to cellular death ${ }^{32}$. The $\mathrm{Bcl}_{2}$ family includes both pro- and anti-apoptotic molecules ${ }^{33}$. Caspase- 3 is a cytoplasmic pro-enzyme and activate the irreversible process of apoptosis ${ }^{34}$. In the present study, we also examined the expression of $\mathrm{Bcl}_{2}$ and Caspase-3 to evaluate the extent of organ damage at the molecular level as a result of heavy metal exposure using qRT-PCR analysis.

Different groups reported the assessment of cardiovascular damage induced by heavy metal exposure using $\mathrm{H}$ \& E staining ${ }^{35,36}$. Cobbina and colleagues reported high toxicity as a result of co-exposure of metals in comparison with the individual metal exposure ${ }^{37}$. In the present study, the heavy metal treatment caused severe damage 

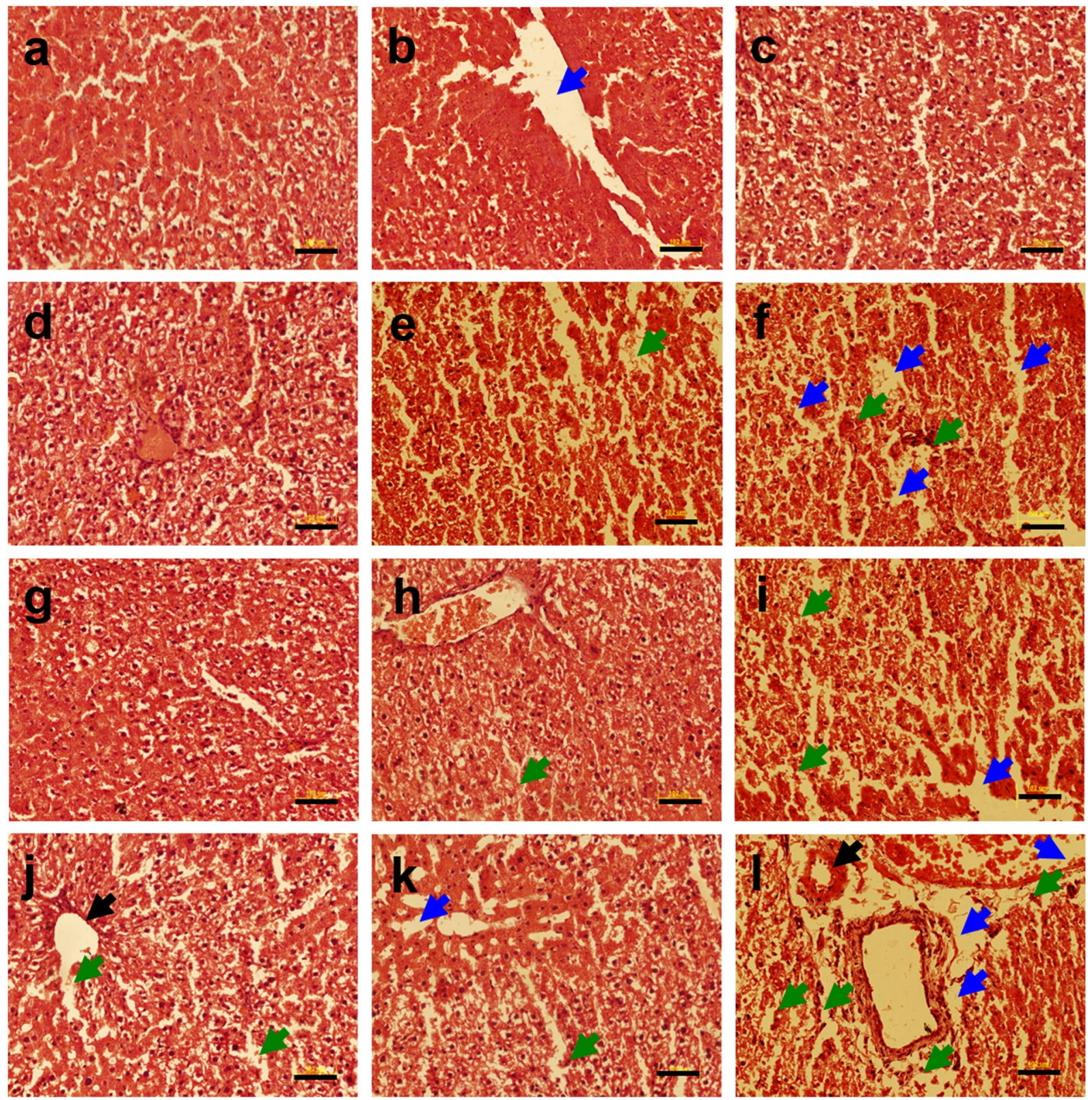

Figure 3. Histopathology of liver tissue of non-diabetic and diabetic rats stained with hematoxylin and eosin (H \& E) following heavy metal exposure. (a) non-diabetic control group (b) non-diabetic arsenic (As)-treated group, (c) non-diabetic cadmium (Cd)-treated group, (d) non-diabetic manganese ( $\mathrm{Mn})$-treated group, (e) non-diabetic lead $(\mathrm{Pb})$-treated group, $(\mathbf{f})$ non-diabetic metal mixture (As $+\mathrm{Cd}+\mathrm{Mn}+\mathrm{Pb})$-treated group, $(\mathrm{g})$ diabetic untreated group, (h) diabetic As-treated group, (i) diabetic Cd-treated group, (j) diabetic Mn-treated group, (k) diabetic $\mathrm{Pb}$-treated group and (l) diabetic metal mixture ( $\mathrm{As}+\mathrm{Cd}+\mathrm{Mn}+\mathrm{Pb}$ )-treated group. Note: All the images represent $\times 20$ magnification and scale bars represent $102 \mu \mathrm{m}$. Further, blue arrows represent vacuolation, green arrows represent cellular degeneration and black arrows represent congestion.

in myocardial tissues of non-diabetic, as well as diabetic Pb-treated and metal mixture treated groups exhibiting irregularly arranged myofibrils and vacuolization assessed by $\mathrm{H} \& \mathrm{E}$ staining. Likewise, metal treatment resulted in a downregulated expression of $\mathrm{Bcl}_{2}$ and up-regulation of Caspase-3 in non-diabetic and diabetic metal treated groups as compared to the non-diabetic untreated control group. Importantly, $\mathrm{Pb}$ and metal mixture treatment resulted in increased cardiac cell apoptosis. Previously, $\mathrm{Xu}$ and colleagues reported that $\mathrm{Pb}$ induces apoptosis in vascular and cardiac tissues ${ }^{35}$.

Fibrosis and tubular degeneration were observed in kidney tissues of Cd-treated, Pb-treated and heavy metal mixture treated non-diabetic as well as diabetic rats. These findings are consistent with qRT-PCR data that heavy metal treatment resulted in a downregulated expression of $\mathrm{Bcl}_{2}$ and significant upregulation of Caspase-3 in non-diabetic and diabetic $\mathrm{Pb}$-treated, $\mathrm{Cd}$-treated, and metal mixture treated groups as compared to the rest of the groups. It is well documented that chronic Cd exposure affects many organ systems and especially kidney has 

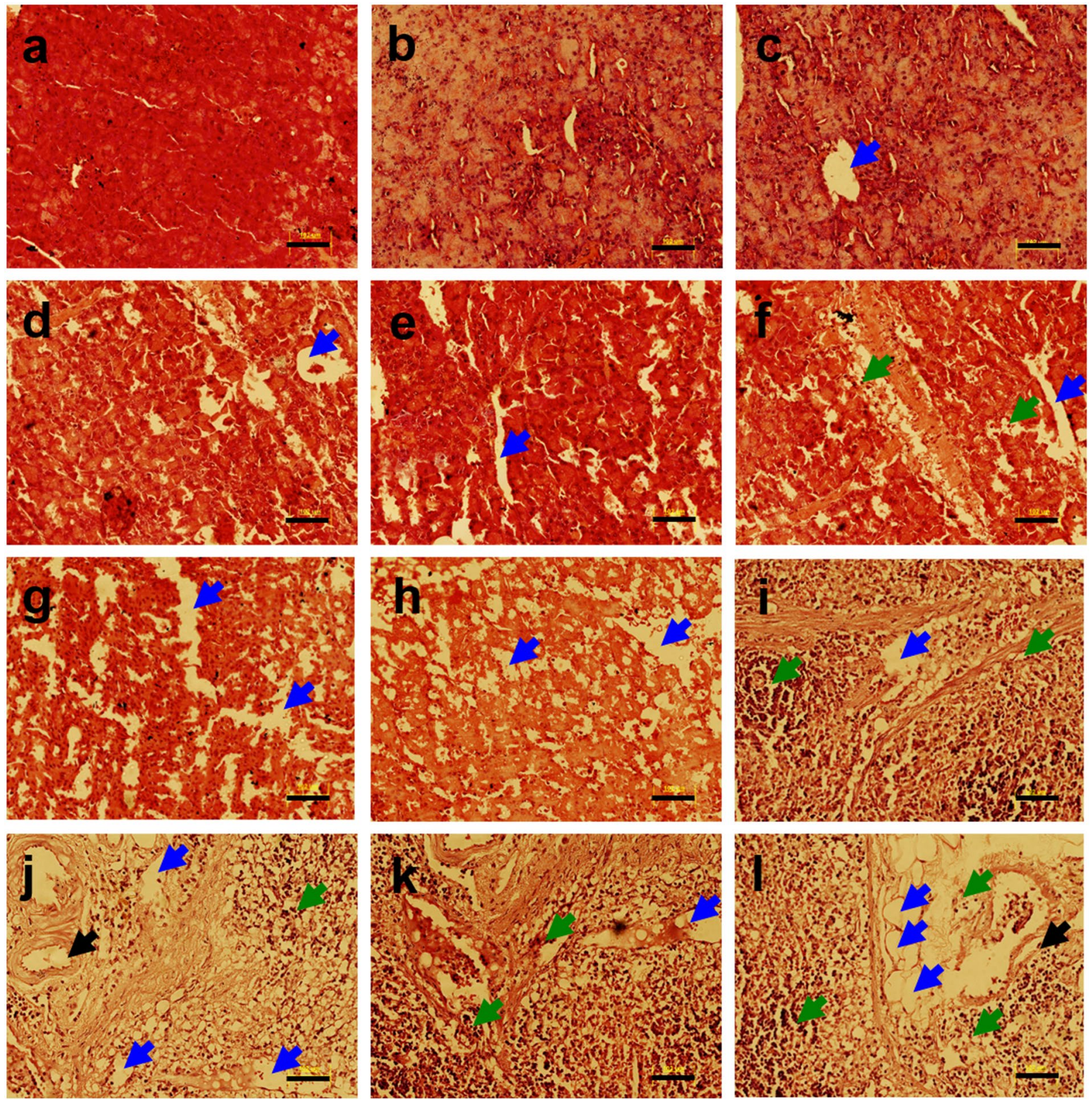

Figure 4. Histopathology of pancreas tissue of non-diabetic and diabetic rats stained with hematoxylin and eosin (H \& E) following heavy metal exposure. (a) non-diabetic control group, (b) non-diabetic arsenic (As)treated group, (c) non-diabetic cadmium $(\mathrm{Cd})$-treated group, $(\mathbf{d})$ non-diabetic manganese $(\mathrm{Mn})$-treated group, $(\mathbf{e})$ non-diabetic lead $(\mathrm{Pb})$-treated group, $(\mathbf{f})$ non-diabetic metal mixture $(\mathrm{As}+\mathrm{Cd}+\mathrm{Mn}+\mathrm{Pb})$-treated group, (g) diabetic untreated group, (h) diabetic As-treated group, (i) diabetic Cd-treated group, (j) diabetic $\mathrm{Mn}$-treated group, (k) diabetic $\mathrm{Pb}$-treated group and (l) diabetic metal mixture ( $\mathrm{As}+\mathrm{Cd}+\mathrm{Mn}+\mathrm{Pb}$ )-treated group. Note: All the images represent $\times 20$ magnification and scale bars represent $102 \mu \mathrm{m}$. Further, blue arrows represent vacuolation, green arrows represent cellular degeneration and black arrows represent congestion.

been a critical target of its toxicity ${ }^{38}$. Different groups have reported $\mathrm{Pb}$ and $\mathrm{Cd}$-induced renal damage $\mathrm{e}^{37,39,40}$. Baş and Kalender reported nephrotoxic effects of lead nitrate in diabetic and non-diabetic rats ${ }^{41}$. The cytotoxic effects such as nuclear DNA fragmentation, apoptotic cell production and mitochondrial apoptotic proteins release following $\mathrm{CdCl}_{2}$ exposure have been reported in the liver and kidney ${ }^{42,43}$. It has been reported that $\mathrm{Pb}$ can induce apoptosis resulting in the imbalance of $\mathrm{Bax}_{\mathrm{BCl}}$, and mitochondrial dysfunction ${ }^{44}$. It has been reported that $\mathrm{Pb}$-induced apoptosis may be a probable mechanism of $\mathrm{Pb}$ toxicity. $\mathrm{Pb}$ exposure induced apoptosis is well known in chicken erythrocytes ${ }^{45}$ and rat proximal tubular cells ${ }^{46,47}$.

The $\mathrm{H} \& \mathrm{E}$ staining of liver tissue showed that heavy metal treatment resulted in cellular degeneration and necrosis in rats. In the liver tissue of metal mixture treated diabetic as well as non-diabetic rats, vacuolation and inflammation were observed in the liver in addition to cellular degeneration. These results are in line with the qRT-PCR data that heavy metal treatment resulted in a downregulated expression of $\mathrm{Bcl}_{2}$ and upregulation 

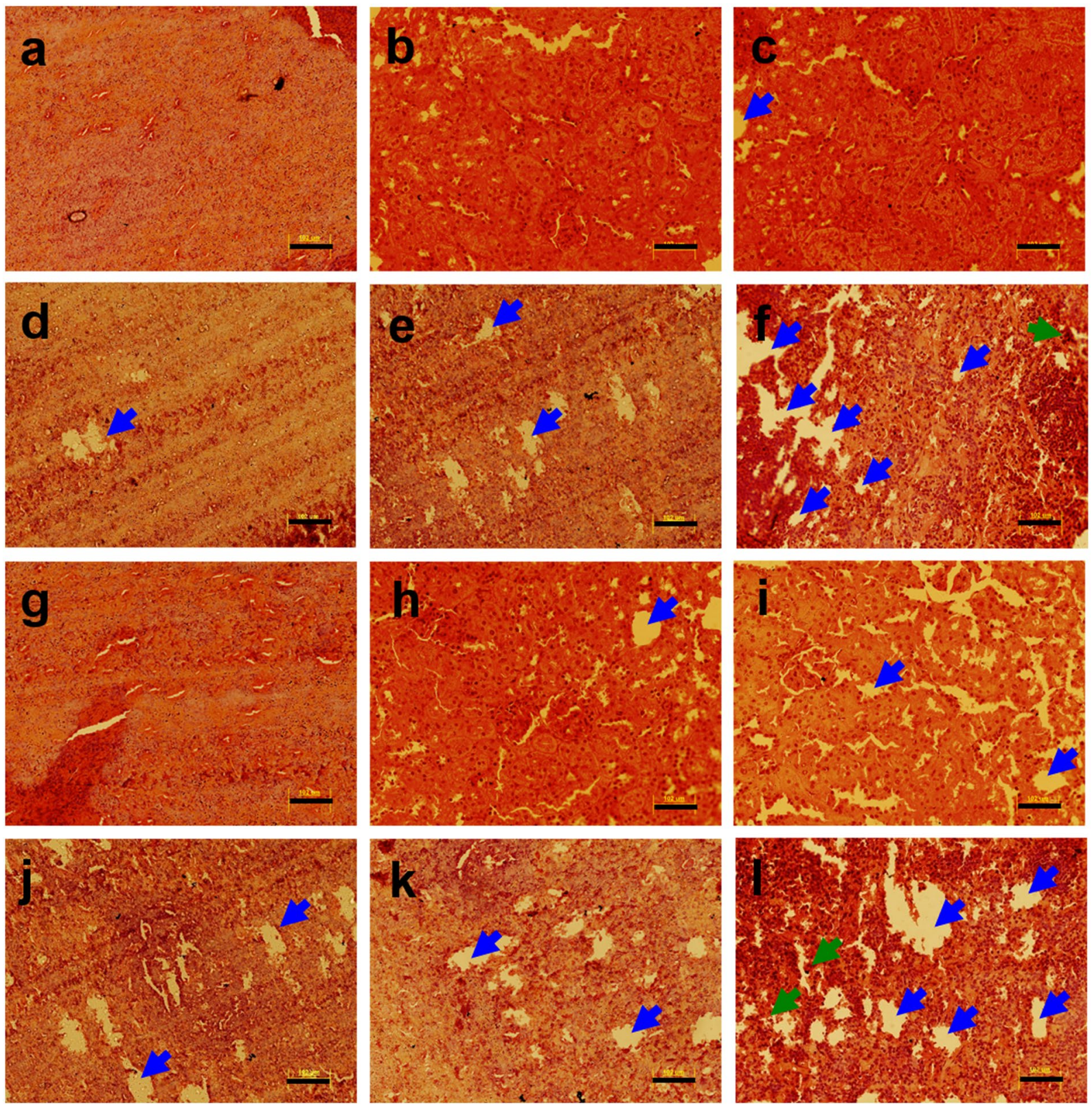

Figure 5. Histopathology of spleen tissue of non-diabetic and diabetic rats stained with hematoxylin and eosin (H \& E) following heavy metal exposure. (a) non-diabetic control group, (b) non-diabetic arsenic (As)-treated group, (c) non-diabetic cadmium (Cd)-treated group, (d) non-diabetic manganese ( $\mathrm{Mn})$-treated group, (e) non-diabetic lead $(\mathrm{Pb})$-treated group, $(\mathbf{f})$ non-diabetic metal mixture (As $+\mathrm{Cd}+\mathrm{Mn}+\mathrm{Pb})$-treated group, $(\mathbf{g})$ diabetic untreated group, (h) diabetic As-treated group, (i) diabetic Cd-treated group, (j) diabetic Mn-treated group, (k) diabetic $\mathrm{Pb}$-treated group and (l) diabetic metal mixture ( $\mathrm{As}+\mathrm{Cd}+\mathrm{Mn}+\mathrm{Pb}$ )-treated group. Note: All the images represent $\times 20$ magnification and scale bars represent $102 \mu \mathrm{m}$. Further, blue arrows represent vacuolation, and green arrows represent cellular degeneration.

of Caspase- 3 in non-diabetic and diabetic metal alone and metal mixture treated groups as compared to the non-diabetic untreated group. Jayawardena and colleagues reported heavy metals $(\mathrm{Cd}, \mathrm{Cr}, \mathrm{Cu}, \mathrm{Pb}$, and $\mathrm{Zn}$ ) exposure resulted in histopathological alterations in amphibians ${ }^{48}$. It has also been reported that the administration of Cd cause severe hepatocyte necrosis, fatty changes, degeneration, and inflammatory cell infiltrations ${ }^{49-51}$.

The streptozotocin injected untreated rats revealed severe degeneration and necrosis in pancreatic tissues. In all the heavy metal treated diabetic rat groups, the histologic sections of pancreatic tissues exhibited severe degeneration, necrosis, degranulation and shrinkage in the islets of Langerhans. The qRT-PCR data also confirmed the histology data that metal treatment resulted in downregulated expression of $\mathrm{Bcl}_{2}$ and upregulation of Caspase-3 in all the heavy metal-treated diabetic rat groups when compared with their respective non-diabetic heavy metal treated groups revealing the fact that heavy metal treatment might worse the organ damage under diabetic conditions. Kanter and colleagues reported the effects of Cd exposure on morphological aspects of the pancreas, in 
streptozotocin-induced diabetic rats ${ }^{52}$. Edwards and Prozialeck reported cytotoxic effects of Cd on the pancreatic $\beta$-cells ${ }^{53}$. Cd has the potential to induce oxidative stress damage resulting in suppression of insulin secretion and apoptosis in pancreatic islet $\beta$-cells in-vitro and in-vivo ${ }^{53}$.

The present study revealed severe congestion in the spleen tissue of the Cd-treated diabetic rats and metal mixture treated non-diabetic and diabetic rats. Severe congestion in the spleen tissue is suggestive of heavy metal mixture induced spleen damage. As treatment resulted in severe downregulated expression of $\mathrm{Bcl}_{2}$ and significant upregulation of Caspase-3 in non-diabetic and diabetic groups as compared to the rest of the groups. In the present study, histological and qRT-PCR data provide an increased understanding of the diabetes dependent damage of lymphoid tissue. Aktug and colleagues evaluated the effects of diabetes on the lymphoid tissue of spleen using immunohistochemistry, qRT-PCR, and light microscope analyses ${ }^{54}$. Zhang and colleagues reported that Cd can induce oxidative stress and apoptosis of spleen by affecting the mitochondrial intrinsic pathway ${ }^{55}$.

In conclusion, the diabetic rats were more prone to metal alone as well as metal mixture induced toxicity as compared to non-diabetic rats. Further, this molecular knowledge may also help in understanding, how different heavy metals individually as well as in combination contribute to organ damage under diabetic and non-diabetic conditions.

\section{Materials and Methods}

Animals. In the present study, the male Wistar rats $(n=60)$ having body weight $(170-220$ grams) were used. We selected male rats for the present study as male individuals working in various foundries (in developing countries) are relatively more exposed to heavy metals as compared to the females and hence males are at high risk as a result of heavy metal exposure. It is also well documented that following streptozotocin treatment, female rats exhibit a more severe form of diabetes with elevated glucose levels, and a worse survival rate as compared to male rats $^{56}$. Another reason to avoid female animals is because of their hormonal fluctuation during the reproductive cycle while males have more stable hormonal status. Because of all the above-mentioned reasons, the male Wister rats were used to study the effects of heavy metals. All experimental protocols were approved by the board of Animal Care, National Centre of Excellence in Molecular Biology, Lahore, Pakistan, and all experiments were performed following approved protocols. Rats were housed at a controlled temperature of $\left(26 \pm 1.5^{\circ} \mathrm{C}\right)$, humidity $(60 \% \pm 5)$ and under 12 hours light/dark schedule.

Development of the diabetic rat model. Type 1 diabetes was induced in male Wistar rats with an intraperitoneal injection of streptozotocin (Sigma Aldrich, USA) at a dose of $40 \mathrm{mg} / \mathrm{kg}$ body weight. Serum glucose levels measured on day 6 and rats with glucose level $\geq 300 \mathrm{mg} / \mathrm{dL}$ were considered as diabetic and were used for subsequent heavy metal exposure.

Heavy metal exposure. The male Wistar rats were divided into the following twelve groups, (1) Non-diabetic control group, (2) Non-diabetic Pb-treated group, (3) Non-diabetic Mn-treated group, (4) Non-diabetic Cd-treated group, (5) Non-diabetic As-treated group, (6) Non-diabetic Pb-, Mn-, Cd-, and As-treated group, (7) Diabetic untreated group, (8) Diabetic Pb-treated group, (9) Diabetic Mn-treated group, (10) Diabetic Cd-treated group, (11) Diabetic As-treated group, (12) Diabetic Pb-, Mn-, Cd- and As-treated group. The $\mathrm{Pb}, \mathrm{Mn}$, and $\mathrm{Cd}$ were injected intraperitoneally while As was administered orally via drinking water. The name of salts used for heavy metals administration and their concentration are described in Table 1. After heavy metal exposure, every alternate day for 30 days, rats were sacrificed by injecting an overdose of anesthesia followed by cervical dislocation, and then the heart, kidney, liver, pancreas, and spleen were harvested and used for subsequent analyses.

Histopathological analysis. The rats were sacrificed and immediately heart, kidney, liver, pancreas and spleen tissues were harvested. Following processing with different grades of ethanol and xylene; liver, kidney, spleen, heart and pancreas tissues were embedded in paraffin wax and stored at $4^{\circ} \mathrm{C}$ for further analysis. The tissue sections were made at $5 \mu \mathrm{m}$ thickness by Microtome (Microm, Germany). Similarly, all tissue sections were mounted on poly-L-lysine-coated microscopic slides. The H \& E staining was performed to examine the morphological changes. Following deparaffinization and rehydration, hematoxylin solution was applied on slides for $2 \mathrm{~min}$ and then washed in running tap water for $5 \mathrm{~min}$. Subsequently, the eosin solution dropped on sections for $30 \mathrm{sec}$ and washed the slides thoroughly by running tap water. Following dehydration, sections were mounted with cytoseal medium (Richard-Allan Scientific, USA). Four fields per section were randomly selected and photographed with the help of the Olympus BX-61 microscope (Olympus, USA). A minimum of four sections $(200 \mu \mathrm{m}$ apart) selected from each organ per animal ( $\mathrm{n}=5$ rats/group) were used for the study.

Gene expression profiling. Following sacrificing rats, the heart, kidney, liver, pancreas and spleen tissues were harvested for gene expression analysis. RNA from tissues was extracted using Trizol reagent (Invitrogen, USA) and quantified with an ND-1000 spectrophotometer (NanoDrop Technologies, USA). cDNA was synthesized from $1 \mu \mathrm{g}$ RNA with the Revert Aid H-Minus first-strand cDNA synthesis kit (Invitrogen, USA) as the manufacturer's protocol.

The qRT-PCR analysis of all heavy metal treated groups, as well as the non-diabetic untreated control group, was carried out for Caspase-3 (apoptotic gene) and $\mathrm{Bcl}_{2}$ (anti-apoptotic gene) using Maxima SYBR Green qPCR Master Mix (Fermentas, USA) according to the manufacturer's protocol and run on PikoReal 96 real-time PCR (Thermo Scientific, USA). The relative gene expression analysis was performed by using PikoReal software (Thermo Scientific). $\beta$-actin was used for normalization. The primers were designed using a real-time PCR tool (Integrated DNA Technologies) and are available upon request. 


\begin{tabular}{|c|c|c|c|}
\hline Sr. No. & Treatment groups & Salt name & Concentration used \\
\hline 1 & $\begin{array}{l}\text { Non-diabetic control } \\
\text { group }\end{array}$ & sterile saline solution & Not applicable \\
\hline 2 & $\begin{array}{l}\text { Non-diabetic } \mathrm{Pb}- \\
\text { treated group }\end{array}$ & $\mathrm{C}_{4} \mathrm{H}_{6} \mathrm{O}_{4} \mathrm{~Pb}$ & $20 \mathrm{mg} / \mathrm{kg}$ \\
\hline 3 & $\begin{array}{l}\text { Non-diabetic Mn- } \\
\text { treated group }\end{array}$ & $\mathrm{MnCl}_{2}$ & $20 \mathrm{mg} / \mathrm{kg}$ \\
\hline 4 & $\begin{array}{l}\text { Non-diabetic Cd- } \\
\text { treated group }\end{array}$ & $\mathrm{CdCl}_{2}$ & $5 \mathrm{mg} / \mathrm{kg}$ \\
\hline 5 & $\begin{array}{l}\text { Non-diabetic As- } \\
\text { treated group }\end{array}$ & $\mathrm{AsO}_{2} \mathrm{Na}$ & $60 \mathrm{mg} / \mathrm{L}$ \\
\hline 6 & $\begin{array}{l}\text { Non-diabetic Pb-, } \\
\text { Mn-, Cd- and As- } \\
\text { treated group }\end{array}$ & $\mathrm{C}_{4} \mathrm{H}_{6} \mathrm{O}_{4} \mathrm{~Pb}+\mathrm{MnCl}_{2}+\mathrm{CdCl}_{2}+\mathrm{AsO}_{2} \mathrm{Na}$ & $\begin{array}{l}20 \mathrm{mg} / \mathrm{kg}+20 \mathrm{mg} / \mathrm{kg} \\
+5 \mathrm{mg} / \mathrm{kg}+60 \mathrm{mg} / \mathrm{L} \\
\text { respectively }\end{array}$ \\
\hline 7 & $\begin{array}{l}\text { Diabetic untreated } \\
\text { group }\end{array}$ & sterile saline solution & Not applicable \\
\hline 8 & $\begin{array}{l}\text { Diabetic } \mathrm{Pb} \text {-treated } \\
\text { group }\end{array}$ & $\mathrm{C}_{4} \mathrm{H}_{6} \mathrm{O}_{4} \mathrm{~Pb}$ & $20 \mathrm{mg} / \mathrm{kg}$ \\
\hline 9 & $\begin{array}{l}\text { Diabetic Mn-treated } \\
\text { group }\end{array}$ & $\mathrm{MnCl}_{2}$ & $20 \mathrm{mg} / \mathrm{kg}$ \\
\hline 10 & $\begin{array}{l}\text { Diabetic Cd-treated } \\
\text { group }\end{array}$ & $\mathrm{CdCl}_{2}$ & $5 \mathrm{mg} / \mathrm{kg}$ \\
\hline 11 & $\begin{array}{l}\text { Diabetic As-treated } \\
\text { group }\end{array}$ & $\mathrm{AsO}_{2} \mathrm{Na}$ & $60 \mathrm{mg} / \mathrm{L}$ \\
\hline 12 & $\begin{array}{l}\text { Diabetic Pb-, Mn-, } \\
\text { Cd- and As-treated } \\
\text { group }\end{array}$ & $\mathrm{C}_{4} \mathrm{H}_{6} \mathrm{O}_{4} \mathrm{~Pb}+\mathrm{MnCl}_{2}+\mathrm{CdCl}_{2}+\mathrm{AsO}_{2} \mathrm{Na}$ & $\begin{array}{l}20 \mathrm{mg} / \mathrm{kg}+20 \mathrm{mg} / \\
\mathrm{kg}+5 \mathrm{mg} / \mathrm{kg}+60 \mathrm{mg} / \mathrm{L} \\
\text { respectively }\end{array}$ \\
\hline
\end{tabular}

Table 1. Details of heavy metal treatments along with the name of salts and their concentration used for heavy metals administration. Note: $\mathrm{C}_{4} \mathrm{H}_{6} \mathrm{O}_{4} \mathrm{~Pb}$ (lead acetate), $\mathrm{MnCl}_{2}$ (manganese chloride), $\mathrm{CdCl}_{2}$ (cadmium chloride) and $\mathrm{AsO}_{2} \mathrm{Na}$ (sodium arsenite).

Statistical analysis. The data were analyzed using the GraphPad Prism 5 software (USA). Results are expressed as mean \pm standard deviation (SD). One-way analysis of variance (ANOVA) followed by Dunnett's post-test was used for analysis. The difference at $\mathrm{p} \leq 0.05$ considered statistically significant.

Received: 25 February 2019; Accepted: 12 March 2020;

Published online: 03 April 2020

\section{References}

1. WHO. Diabetes. Geneva, Switzerland: World Health Organization. (2019).

2. CDC. Incidence of diagnosed diabetes. (2019).

3. Heindel, J. J. et al. Metabolism disrupting chemicals and metabolic disorders. Reprod. Toxicol. Elmsford. N 68, 3-33 (2017).

4. Sargis, R. M. et al. THE DIABETES EPIDEMIC: Environmental Chemical Exposure in Etiology and Treatment. San. Franc. Med. 85, $18-20(2012)$

5. Thayer, K. A. et al. Role of environmental chemicals in diabetes and obesity: a National Toxicology Program workshop review. Environ. Health Perspect. 120, 779-789 (2012).

6. Chandel, M. \& Jain, G. Manganese induced hematological alteration in Wistar rats. J. Environ. Occup. Sci. 5, 77 (2016).

7. Ali, M. F. \& Taha, M. Pathological and hematological studies on the effect of curcumin on manganese chloride-induced neurotoxicity in rats. Comp. Clin. Path. 1, 1-14 (2019).

8. Iavicoli, I. et al. The effects of metals as endocrine disruptors. J. Toxicol. Environ. Health B. Crit. 12(3), 206-23 (2009).

9. Leyssens, L. et al. Cobalt toxicity in humans-A review of the potential sources and systemic health effects. Toxicology 387, 43-56 (2017).

10. De Souza Machado, A. A. et al. Unravelling metal mobility under complex contaminant signatures. Sci. Total Environ. 622-623, 373-384 (2017).

11. Tchounwou, P. B. et al. Heavy metals toxicity and the environment. EXS. 101, 133-164 (2012).

12. Alonso-Magdalena, P. et al. Toxic effects of common environmental pollutants in pancreatic $\beta$-cells and the onset of diabetes mellitus. Encyclopedia of endocrine conditions 2(1), 764-775 (2019).

13. Simona, C. et al. Development of a New Sequential Extraction Procedure of Nickel Species on Workplace Airborne Particulate Matter: Assessing the Occupational Exposure to Carcinogenic Metal Species. Int.J. Analyt. Chem. 1-9 (2018).

14. Chen, Y. et al. Blood lead and cadmium levels associated with hematological and hepatic functions in patients from an e-wastepolluted area. Chemosphere. 220, 531-538 (2018).

15. Kelly, B. C. et al. Human exposure to trace elements in central Cambodia: Influence of seasonal hydrology and food-chain bioaccumulation behaviour. Ecotoxicol. Environ. Saf. 162, 112-120 (2018).

16. Jarup, L. Hazards of heavy metal contamination. Br. Med. Bull. 68, 167-182 (2003).

17. Rehman, K. et al. Prevalence of exposure of heavy metals and their impact on health consequences. J. Cell Biochem. 119(1), 157-184 (2018).

18. Singh, N. et al. Biochemical and Molecular Bases of Lead-Induced Toxicity in Mammalian Systems and Possible Mitigations. Chem. Res. Toxicol. 31, 1009-1021 (2018).

19. Yu, S. et al. Immunological dysfunction in chronic arsenic exposure: From subclinical condition to skin cancer. J. Dermatol. 45, 1271-1277 (2018).

20. Akar, Y., Ahmad, N. \& Khalıd, M. The effect of cadmium on the bovine in vitro oocyte maturation and early embryo development. Int. J. Vet. Sci. Med. 6, S73-S77 (2018). 
21. Nkpaa, K. W. et al. Ethanol via Regulation of NF- $\kappa B / p 53$ Signaling Pathway Increases Manganese-Induced Inflammation and Apoptosis in Hypothalamus of Rats. Biol. Trace Elem. Res. 1, 1-8 (2018).

22. Riaz, M. A. et al. Metal-induced nephrotoxicity to diabetic and non-diabetic Wistar rats. Environ. Sci. Pollut. Res. Int. 26(30), 31111-31118 (2019).

23. Le Magueresse-Battistoni, B., Vidal, H. \& Naville, D. Environmental Pollutants and Metabolic Disorders: The Multi-Exposure Scenario of Life. Front. Endocrinol. 9, 582 (2018)

24. Heindel, J. J. et al. Metabolism disrupting chemicals and metabolic disorders. Reproductive Toxicol. 68, 3-33 (2017).

25. Seitz, S. et al. Chemotherapy-induced apoptosis in hepatocellular carcinoma involves the p53 family and is mediatedviathe extrinsic and the intrinsic pathway. Int. J. Cancer. 126, 2049-2066 (2010).

26. Bivik, C., Rosdahl, I. \& Ollinger, K. Hsp70 protects against UVB induced apoptosis by preventing release of cathepsins and cytochrome c in human melanocytes. Carcinogenesis 28, 537-544 (2006).

27. Zhang, J., Zhang, H. \& Ni, W. Oxidative stress and apoptosis of Carassius auratus lymphocytes induced by nonplanar (PCB153) and coplanar (PCB169) polychlorinated biphenyl congeners in vitro. J. Environ. Sci. 21, 1284-1289 (2009).

28. Zhang, L., Li, L. \& Zhang, G. Gene discovery, comparative analysis and expression profile reveal the complexity of the Crassostrea gigas apoptosis system. Dev. Comp. Immunol. 35, 603-610 (2011).

29. Solhaug, A. Polycyclic aromatic hydrocarbons induce both apoptotic and anti-apoptotic signals in Hepalclc7 cells. Carcinogenesis. 25, 809-819 (2003).

30. Pathak, N., Mitra, S. \& Khandelwal, S. Cadmium Induces Thymocyte Apoptosis via Caspase-Dependent and Caspase-Independent Pathways. J. Biochem. Mol. Toxicol. 27, 193-203 (2013).

31. Luzio, A. et al. Copper induced upregulation of apoptosis related genes in zebrafish (Danio rerio) gill. Aquat. Toxicol. 128-129, 183-189 (2013)

32. Sokolova, I. M. Cadmium-induced apoptosis in oyster hemocytes involves disturbance of cellular energy balance but no mitochondrial permeability transition. J. Exp. Biol. 207, 3369-3380 (2004).

33. Bhola, P. D. \& Letai, A. Mitochondria Judges and Executioners of Cell Death Sentences. Mol. Cell. 61, 695-704 (2016).

34. Larsen, B. D. et al. Caspase 3/caspase-activated DNase promote cell differentiation by inducing DNA strand breaks. Proc. Natl. Acad. Sci. 107, 4230-4235 (2010).

35. Xu, L. et al. Lead Induces Apoptosis and Histone Hyperacetylation in Rat Cardiovascular Tissues. PLOS ONE 10, e0129091 (2015).

36. Ghosh, K. \& N, I. Cadmium treatment induces echinocytosis, DNA damage, inflammation, and apoptosis in cardiac tissue of albino Wistar rats. Environ. Toxicol. Pharmacol. 59, 43-52 (2018).

37. Cobbina, S. J. et al. Toxicity assessment due to sub-chronic exposure to individual and mixtures of four toxic heavy metals. J. Hazard Mater. 294, 109-120 (2015).

38. Hagar, H. \& Al Malki, W. Betaine supplementation protects against renal injury induced by cadmium intoxication in rats: Role of oxidative stress and caspase-3. Environ. Toxicol. Pharmacol. 37, 803-811 (2014).

39. Aslam, M. et al. Nephroprotective action of Peucedanumgrande against cadmium chloride induced renal toxicity in wistar rats. EXCLI J. 11, 444 (2012).

40. Oyagbemi, A. A. et al. Lack of reversal of oxidative damage in renal tissues of lead acetate-treated rats. Environ. Toxicol. 30, 1235-1243 (2014).

41. Baş, H. \& Kalender, Y. Nephrotoxic effects of lead nitrate exposure in diabetic and nondiabetic rats: Involvement of oxidative stress and the protective role of sodium selenite. Environ. Toxicol. 31, 1229-1240 (2015).

42. Lemarié, A. et al. Cadmium induces caspase-independent apoptosis in liver Hep3B cells: role for calcium in signaling oxidative stress-related impairment of mitochondria and relocation of endonuclease $\mathrm{G}$ and apoptosis-inducing factor. Free Radic. Biol. Med. 36, 1517-1531 (2004).

43. Liu, Y. \& Templeton, D. M. Initiation of caspase-independent death in mouse mesangial cells by $\mathrm{Cd} 2+$ : Involvement of $\mathrm{p} 38$ kinase and CaMK-II. J. Cell. Physiol. 217, 307-318 (2008).

44. Xu, J., Ji, L. D. \& Xu, L. H. Lead-induced apoptosis in PC 12 cells: Involvement of p53, Bcl-2 family and caspase-3. Toxicol. Lett. 166, 160-167 (2006).

45. Hiraga, T. et al. Lead exposure induces pycnosis and enucleation of peripheral erythrocytes in the domestic fowl. Vet. J. 178, 109-114 (2008).

46. Wang, L. et al. Simultaneous Effects of Lead and Cadmium on Primary Cultures of Rat Proximal Tubular Cells: Interaction of Apoptosis and Oxidative Stress. Arch. Environ. Contam. Toxicol. 61, 500-511 (2011).

47. Wang, H. et al. Redistribution of subcellular calcium and its effect on apoptosis in primary cultures of rat proximal tubular cells exposed to lead. Toxicol. 333, 137-146 (2015).

48. Jayawardena, U. A. et al. Heavy metal-induced toxicity in the Indian green frog: Biochemical and histopathological alterations. Environ. Toxicol. Chem. 36, 2855-2867 (2017).

49. Gong, P. et al. Endomorphin 1 effectively protects cadmium chloride-induced hepatic damage in mice. Toxicol. 251, 35-44 (2008).

50. Ersan, Y., Ari, İ. \& Koç, E. Effects of cadmium compounds (cadmium para hydroxybenzoate and cadmium chloride) on the liver of mature mice. Turk. J. Zoo. 32, 115-119 (2008).

51. Renugadevi, J. \& Prabu, S. M. Cadmium-induced hepatotoxicity in rats and the protective effect of naringenin. Exp. Toxicol. Pathol. 62, 171-181 (2010).

52. Kanter, M. et al. Effects of Cadmium Exposure on Morphological Aspects of Pancreas, Weights of Fetus and Placenta in Streptozotocin-Induced Diabetic Pregnant Rats. Biol. Trace Elem. Res. 93, 189-200 (2003).

53. Edwards, J. R. \& Prozialeck, W. C. Cadmium, diabetes and chronic kidney disease. Toxicol. Appl. Pharmacol. 238, 289-293 (2009).

54. Aktuğ, H. et al. Streptozotosine bağlıdiabetik rat larındalakdo kusunda caspase-3 ve bcl-2 ekspresyonlarının immune histokimyasal ve kantitatif RT-PCR ile değerlendirilmesi. Ege. Tip. Dergisi. 49 (2010).

55. Zhang, M. et al. Alterations in antioxidant function and cell apoptosis in duck spleen exposed to molybdenum and/or cadmium. J. Vet. Sci. 18(2), 193-200 (2017).

56. Vital, P., Larrieta, E. \& Hiriart, M. Sexual dimorphism in insulin sensitivity and susceptibility to develop diabetes in rats. J Endocrinol. 190(2), 425-32 (2006).

\section{Acknowledgements}

We are highly thankful to Director National Centre of Excellence in Molecular Biology, University of Punjab, Lahore, Pakistan.

\section{Author contributions}

M.A.R., Z.U.N., and A.M. were responsible for the study design. A.R. and A.B.T.K. contribute to manuscript writing. M.A.R., M.S.A., and H.B. contributed to the execution of the study. All authors reviewed and approved the manuscript. M.A.R. accepts responsibility as the corresponding author. 


\section{Competing interests}

The authors declare no competing interests.

\section{Additional information}

Supplementary information is available for this paper at https://doi.org/10.1038/s41598-020-62807-0.

Correspondence and requests for materials should be addressed to M.A.R.

Reprints and permissions information is available at www.nature.com/reprints.

Publisher's note Springer Nature remains neutral with regard to jurisdictional claims in published maps and institutional affiliations.

(c) (i) Open Access This article is licensed under a Creative Commons Attribution 4.0 International License, which permits use, sharing, adaptation, distribution and reproduction in any medium or format, as long as you give appropriate credit to the original author(s) and the source, provide a link to the Creative Commons license, and indicate if changes were made. The images or other third party material in this article are included in the article's Creative Commons license, unless indicated otherwise in a credit line to the material. If material is not included in the article's Creative Commons license and your intended use is not permitted by statutory regulation or exceeds the permitted use, you will need to obtain permission directly from the copyright holder. To view a copy of this license, visit http://creativecommons.org/licenses/by/4.0/.

(C) The Author(s) 2020 